\title{
La dramaturgia anarquista en Chile: ¿un discurso ideológico?'
}

\section{Anarchistic Drama in Chile: An Ideological Discourse?}

\author{
Sergio Pereira Poza \\ Departamento de Lingüística y Literatura \\ Universidad de Santiago de Chile. Santiago, Chile \\ spereira@usach.cl
}

Resumen • El artículo es una revisión de las condiciones histórico-culturales que explican las razones por las cuales el anarquismo rechaza la ideología como forma de representación de la realidad. En lo que respecta a la crítica de la ideología, se deja en claro que este concepto es visto como una especie particular de mediación simbólica que opera directamente en la esfera social por medio de un discurso que representa los intereses de legitimación de los grupos de poder. El objeto escogido para certificar la superación del ideologismo en la textualidad libertaria es la obra dramática anarquista chilena, la cual elimina la distancia que separa el arte de la vida a través de lo que se denomina el arte en situación.

Palabras clave: Crítica de la ideología, estética de la desideologización, realismo socialista libertario.

Abstract - This article is a revision of the cultural and historical factors that account for the reasons by which anarchism rejects ideology as a form of representing reality. As for criticism on ideology, it is clear that this concept can be seen as a specific type of symbolic mediation operating directly on the social sphere by means of a discourse that represents the legitimatization interests of power groups. In this research the object chosen to certify overcoming ideologism in a dramatic text is the Chilean anarchist drama, which eliminates the gap between art and life through what is known as art in context.

Keywords: criticism on ideology, deideologization aesthetics, libertarian socialist realism.

\footnotetext{
Proyecto núm. 1070128: «La dramaturgia anarquista en Chile. Un discurso de resistencia», financiado por el Fondo Nacional de Ciencia y Tecnología, Fondecyt. Investigador responsable: Sergio Pereira.
} 
La irrupción del anarquismo en Chile en el último tercio del siglo XIX generó al interior de la sociedad un contrapeso cultural, cuyo principal resultado fue el de instalar un espíritu de resistencia contra lo establecido, el cual alcanzó eco en los sectores de la población más refractarios al sistema de ideas imperante. La primera acción consistió en crear un espacio alternativo que implicara la producción y distribución de sus propios bienes simbólicos por carriles paralelos al oficial. Gracias a esto, la historia cultural en Chile registró, por vez primera en lo que llevaba recorrido del siglo el régimen republicano, un pensamiento que aportó contenido específico al proceso de construcción de una realidad diferente a la que aparecía sancionada por la oligarquía. La resistencia libertaria no sólo reaccionaba a los códigos hegemónicos que controlaban los significados y sustentaban la visión unívoca del mundo; también se pronunciaba acerca de la validez de las predicaciones con las que se acostumbraba a revestir la imagen de mundo establecida. El reparo central a este orden burgués se fundaba en el rechazo a un discurso totalizante que encomiaba las bondades de un sistema de creencias excluyente, que nunca discutió la validez de sus certezas, llevado más bien por un claro afán de perpetuación. Esta mirada crítica a lo acordado suponía desarrollar un programa de acción que testimoniara el apego de los anarquistas a la diversidad, promoviendo ideas, principios, valores, morales, rituales sociales y visiones de mundo que gestaran sus propios universos de sentido. El espectro visible que pretendía cubrir la práctica libertaria lo conformaba el segmento más expuesto de la sociedad, los obreros y su entorno familiar y comunal, paciente de un modelo que basaba su consistencia en la lógica de la dominación. Para llevar adelante su tarea, el anarquismo organizó y fortaleció un primer frente asociado con los procesos de comunicación de la palabra libertaria que marcaran el acento en lo que denominaremos la estética de la resistencia. Mientras, por una parte, se buscaba la difusión de las ideas ácratas, por la otra, se buscaba producir un efecto en el destinatario virtual que lo hiciera reaccionar ante una andanada de significaciones y referentes, cuyo fin último era el de la legitimación del Estado burgués. A partir de esta estética del rechazo, el anarquismo implementó un conjunto de auxiliares de mediación simbólica como la prensa, el teatro, la conferencia, la oratoria y la literatura, que actuaran de manera directa en la voluntad de emancipación de la diáspora social y cultural. A los órganos de prensa burgueses, el anarquismo opuso un operativo de divulgación a través de los diarios, revistas y folletos que las distintas unidades ácratas desarrollaron a lo largo del país. A la práctica teatral canónica respaldada por los códigos realistas de la cultura romántico-realista, el anarquismo respondió con una propuesta de mundo inspirada en la universalidad del género humano. Al discurso convencional de reafirmación de la identidad cultural y del proyecto histórico nacional, la resistencia cultural se afirmó en el proyecto de construcción de un nuevo orden, más justo y solidario que el actual. A la pieza tribunicia concebida para persuadir sobre los beneficios distributivos y las compensaciones del modelo imperante, la oratoria libertaria puso de relieve las contradicciones que afectaban a las condiciones de existencia de la sociedad. Finalmente, al discurso literario, validado y sustentado en dos milenios de monoculturalidad, el libertarismo opuso una escritura que se realizara dentro del marco de un arte en situación, espontáneo, centrado en el momento y el lugar y más próximo al arte de la vida.

La contracultura que significó la presencia del anarquismo en Chile implicó, en los hechos, una apertura, si no manifiesta en todos los casos, a lo menos implícita, de nuevos espacios donde se pudiese pensar de manera diferente aquello que la institucionalidad ofrecía como única respuesta válida a las interrogantes del presente factual. El entro- 
nizamiento de la cultura libertaria dentro del rígido y hegemónico orden prevaleciente radicalizó la segmentación polarizada de la sociedad, con resultados manifiestos en las prácticas enunciativas de los discursos de la época, caracterizados por visiones antagonizadas de la realidad. La dicotomía se materializó en el despliegue de dos espacios culturales opuestos que luchaban, en cada caso, por intervenir en el control de las definiciones y en la imputación de significados a la realidad existente. La opción del anarquismo fue la de establecer una textualidad de insurgencia cultural que contuviera las respuestas alternativas a las profundas asimetrías generadas por un modelo de desarrollo industrial que no satisfacía ni siquiera las necesidades primarias del segmento olvidado de la población. Si bien esta lucha estuvo centrada en copar aquellos niveles de expresión que confirieran validez a sus respectivos proyectos históricos, la diferencia entre ambos frentes estuvo, por un lado, en la persistencia de los grupos privilegiados por legitimar sus propuestas de mundo, heredadas de los proyectos fundacionales de la institucionalidad republicana, y, por el otro, restablecer los términos de la auténtica realidad, distorsionados históricamente por las élites por razones de perpetuación de dichos proyectos.

Dos formas de definición del mundo se confrontaban, entonces, en esta constelación de sentidos. Mientras el sistema capitalista burgués se jugaba por una configuración estatal ya dada, probada y evaluada por la tradición y la experiencia, el modelo libertario apostaba por un orden social real en permanente construcción, cuya solución de continuidad aparecía asociada a la consolidación de un fundamento capaz de reeditar los principios humanitaristas de la Ilustración, transados por el liberalismo burgués posrevolucionario por cuotas de poder. Estas dos formas se confrontaban cada vez que había que definir el papel del sujeto en el proceso de construcción de la realidad. En el primer caso, la responsabilidad de formar una conciencia del mundo era asumida por la institucionalidad vigente, cuyo imperativo heteronómico se traducía en la imposición de condiciones de existencia que se correspondía con los intereses y propósitos de los grupos privilegiados; en el segundo caso, el dar cuenta de la realidad quedaba radicado en los procesos internos del propio sujeto, una vez que éste estaba consciente de sus propios procesos vitales, de los cuales no se excluía tampoco la operación de producir sus ideas, creencias, valores y visiones. Del primero, se infiere la intención de ejercer dominio sobre la sociedad o parte de ella mediante el mecanismo político del control, y ello se manifiesta a través de la supremacía intelectual que ostentaba la minoría dominante, lo que quedaba reflejado en la acción envolvente de los sistemas de mediación simbólica que terminaban por condicionar la estructura mental de los dominados. El producto final de esta estrategia heteronómica era la ideología. Del segundo caso, se desprendía la voluntad de trabajar individualmente una «idea» del mundo que partiera de la base concreta de la existencia de manera de no perder de vista "su conexión a tierra», es decir, su cercanía a la vida real. Cualquiera desconexión con la realidad llevaría inevitablemente la «idea» al terreno especulativo, ámbito natural de la ideología (Ricoeur, 2006: 65).

En este trabajo nos interesa certificar que el anarquismo construye su discurso emancipador como forma de resistencia cultural a toda maniobra de distorsión o falseamiento de la realidad que las élites gobernantes realizan con propósitos de legitimación y perpetuación de su orden de poder. La oposición ácrata a estos procedimientos burgueses de deformación discursiva se traduce en una práctica de desideologización de su propio pensamiento y de su propia escritura. Para los libertarios, la ideología es la justificación para perseguir y reprimir la cultura insurgente de los rebeldes que censuran el ocultamiento deliberado de los antagonismos nacidos del capitalismo industrial. Esta resistencia cultural se canaliza en Chile a través de un conjunto de mecanismos de mediación de 
bienes simbólicos como la prensa, la oratoria, la conferencia, los centros e institutos y el arte. Nos importa, en esta ocasión, dar cuenta del papel que le corresponde a la dramaturgia anarquista local en el proceso de desenmascaramiento del Estado oligárquico en sus operaciones de justificación y legitimación de su dominio. La constatación de que la obra dramática tradicional no era más que la caja de resonancia de aquel ente político que fundaba su existencia en la lógica de la dominación, el anarquismo combatirá el arte comprometido, creando un arte nuevo que se desarrolle libre de reglas que lo limiten y que represente la experiencia de vida de las grandes mayorías excluidas del sistema.

\section{EL ANARQUISMO COMO CONCIENCIA EMANCIPADORA}

El anarquismo, genéticamente comprometido con el fragor de las luchas sociales, políticas, económicas y culturales a lo largo de todo el siglo XIX en Europa, llegó a Chile precedido de un historial que lo colocaba entre los primeros movimientos de cuño socialista que proclamaban la abolición del Estado por su responsabilidad histórica de ser el causante de las divisiones sociales y materiales surgidas en el seno de las sociedades modernas. Si bien es cierto que en el continente latinoamericano los efectos de una modernización generalizada todavía no provocaban la polarización de clases, que en otros lugares era fuente de convulsiones sociales y políticas, no podía soslayarse, sin embargo, el clima de crispación que ya se advertía en diversas regiones del continente que preanunciaban lo que en los escritos del marxismo se denominó la «lucha de clases». En Chile, la implantación de un modelo de desarrollo capitalista por los grupos dirigentes desde los albores de la República, profundizaba las contradicciones que se hacían patentes, por más que el relato oficial intentara disimular sus alcances mediante discursos que no escatimaban acciones para promover ideas que reafirmaran el sentido nacional del proyecto histórico que las minorías sustentaban. Los diarios y revistas coincidían en difundir aquellas imágenes, gratas al poder, que encarecían las creencias, valores, principios, concepciones y costumbres que la palabra institucional consideraba legítimas y, por lo mismo, necesarias para construir una sociedad justa y perfecta. Una apelación como ésta cerraba cualquiera opción por inscribir una imagen distinta, ya que cualquiera señal de diversidad cultural se la consideraba enemiga del progreso y motivadora de conatos de fricción en el tejido social.

El anarquismo se insertó en este escenario, atravesado por tensiones y conflictos, luchando por desterrar toda práctica institucional que condujera al sometimiento de las mayorías por voluntad de las élites gobernantes. Su respuesta estuvo a la altura de los intentos de sometimiento cultural de los sectores dominantes, articulando una red social capaz de resistir los embates ideológicos encaminados a seducir, mediante imposturas, al resto de la sociedad. Más que una acción directa destinada a revertir de hecho las condiciones materiales que sobrellevaban los asalariados por el sistema de antagonismos generado por la lógica de la dominación de una clase por otra, el movimiento ácrata entendió que, mientras el proletario y trabajador urbano y rural no adquirieran un conocimiento objetivo de las condiciones materiales en que vivían y producían, la reparación de su dignidad violentada seguiría esperando por generaciones, tal como había ocurrido históricamente con los subalternos al servicio de todos los órdenes de propiedad conocidos, desde las estructuras tribales, pasando por las feudales y comunales, hasta las 
capitalistas burguesas. ${ }^{2}$ Había que educar a los individuos concretos para aprender lo que ellos son y no lo que otros dicen que son. Este objetivo sólo podría ser cubierto por un plan alternativo de adoctrinamiento que desterrara de las conciencias sometidas los prejuicios ideológicos del discurso central. Por este camino, el hombre alcanzaría los niveles de existencia dentro de condiciones materiales que le permitieran producir sus medios de subsistencia, producir su propia textualidad, luchar por ganarse su sustento y, por extensión, contribuir al cambio de un sistema por otro, acercándose de manera resuelta a la instauración «del mejor de los mundos posibles».

La vocación libertaria no sólo se fomentaba a través de la institución educativa, siguiendo los postulados de la enseñanza libre del barcelonés Francisco Ferrer y Guardia. También participaba de este plan de emancipación mental y espiritual el resto de las expresiones culturales libertarias, que iban desde los centros de reflexión, las sociedades de resistencia, las mancomunales y las filarmónicas. En todas ellas, se enseñaba a resistir la palabra engañosa y el propósito encubierto del discurso ideológico que producía una imagen de realidad conteste con los intereses de los grupos privilegiados. Se enseñaba a identificar el sistema desde el cual se gestaba la ideología, el cual aparecía ensamblado con las medidas de control emanadas desde el poder central, representado por el Estado. La tarea inmediata, en consecuencia, era su eliminación, creando, a cambio, un mecanismo igualitario de acceso a los medios de producción. La posición libertaria era refrendada, además, por el resto de los movimientos socialistas de la primera parte del siglo XIX en Europa, en especial, la vertiente del socialismo marxista, cuyo concepto de ideología llega a convertirse en el paradigma dominante en el Occidente (Ricoeur, 2006: 13). Su lucha, a partir de las primeras décadas de ese siglo, se focalizó en el fenómeno social de las desigualdades provocadas por un capitalismo inhumano y expoliador que se extendía por todo el viejo continente como reguero de pólvora. Estas coincidencias producidas en medio de estas inestabilidades sociales explican el trasvasije de contenidos programáticos que suelen observarse en las formulaciones de anarquistas y marxistas durante toda la época de la década de los cuarenta en la que Marx y Bakunin comparten la crítica de la religión y de la política, como legado de las prácticas de dominio de la institucionalidad burguesa. Sintonía en los modos de revisión crítica de la realidad social de ese momento se ve en el reconocimiento de Marx a la existencia de otras vertientes del socialismo que asumen un compromiso similar al del comunismo de abolir la propiedad privada, de entre las cuales menciona al socialismo «de Fourier, Prouhdon, etc.» (Marx, Cartas) $)^{3}$ e inclusive, reconoce el socialismo progresista de Bakunin, algunos años antes, por cierto, de que el pensador libertario se convierta en el centro de sus diatribas y descalificaciones. ${ }^{4}$ Es el propio Marx el que, en el «Manifiesto del Partido Comunista» de 1848, saca a la superficie la problemática social que afecta al hombre a causa de las relaciones históricas

\footnotetext{
2 Karl Marx y Friedrich Engels, La ideología alemana. Los originales de esta obra son de 1845, y se encuentran publicados en forma de Primer Capítulo, dividido en cuatro secciones en el sitio www.marxist.org. En este artículo se usa la edición que se encuentra en la bibliografía.

3 Karl Marx, “Carta a Arnold Ruger”, septiembre de 1843. Bajado del sitio Internet www.marxist.org. Las diferencias mayores de ambas ramas del socialismo surgieron a raíz del ingreso de Bakunin a la Asociación Internacional de Trabajadores (la Primera Internacional) en 1868, quien, como lo narra Marx, se proponía establecer una Segunda Internacional al interior de la misma bajo el nombre de "Alianza de la Democracia Socialista». V. K. Marx, «Carta a Friedrich Bolte» (1871) en <www.marxist.org>.

4 En la «Biografía» que Mintz acompaña a su edición, se citan las palabras de Marx sobre Bakunin: «Es uno de los pocos hombres en quien después de dieciséis años [9 en la cárcel, 4 en relegación, 3 en actividad revolucionaria], constato progreso y no retroceso» (Mintz, ed., 2006: 16).
} 
de los individuos en torno a los diferentes tipos de propiedad. En los párrafos iniciales del Manifiesto, Marx describe esta realidad: «Toda la historia de la sociedad humana, hasta la actualidad, es una historia de luchas de clases» (Kohan, 2003: 18), visión que, más tarde, Bakunin reiterará, desde su perspectiva libertaria, en «El Programa de la Fraternidad» en 1865: «[...] Así no le queda más que una sola vía, la de su emancipación por la práctica. ¿Cuál puede y debe ser esta práctica? No hay más que una. Es la de la lucha solidaria de los obreros contra los patrones» (Mintz, 2006: 70).

Establecidas estas articulaciones teóricas entre ambos pensamientos, no resulta extraño, por lo tanto, determinar grados de interinfluencia de estas dos vertientes socialistas que, a lo menos, en estas fases preliminares del proceso de consolidación del socialismo, compartieron esfuerzos para excluir al Estado de sus tradicionales posiciones de dominio y de capitalización ideológica. Por cierto que estas convergencias de propósitos fueron de corta vida luego que surgieran discrepancias respecto del papel futuro que ambas corrientes asignaban al Estado burgués. A este respecto, Noam Chomski precisa: «La cuestión de la conquista o destrucción del poder del Estado era para Bakunin el asunto primordial que lo separaba de Marx» (2003: 17). Bakunin no veía mayor diferencia entre la dictadura revolucionaria propiciada por los marxistas-leninistas de la época de la revolución de octubre y la institución del Estado. Representaban ambas por igual la inspiración reaccionaria que las atravesaba, "pues — según el teórico libertario-, el resultado de una y otra es la afirmación directa e infalible de los privilegios políticos y económicos de la minoría dirigente y de la esclavitud política y económica de las masas del pueblo» (Mintz, 2006: 74). No obstante lo anterior, queda en pie, de todas maneras, la importancia que los ácratas atribuyeron a las consideraciones del Marx del «Manifiesto del Partido Comunista» y de La ideología alemana (1932) respecto de la necesidad de salir al paso a la lógica de la dominación que se desprendía del proyecto histórico de la burguesía europea.

\section{LA IDEOLOGÍA COMO DISPOSITIVO CULTURAL HEGEMÓNICO}

La resistencia del anarquismo a toda lógica de dominación se explicitó desde sus comienzos como otra de las formas de distanciamiento que quiso marcar el movimiento con sus congéneres socialistas. ${ }^{5}$ La superposición jerárquica de poderes colisionaba con los atributos de libertad que inspiraban las relaciones sociales, pero, además, se la rechazaba porque aparecía como un mecanismo de control de las existencias y de las mentes con el objeto de legitimar el poder y profundizar la supremacía política. Poco o nada podía hacer el espíritu libertario en este terreno, impotencia que se agudizaba aún más al no contar con los medios de penetración comunicativa efectivos que neutralizaran la cosmovisión totalizante de la centralidad. A ese paso, cualquiera determinación de los ácratas en el sentido de establecer sus propios modos de significación chocaban con la acción invasiva de los medios de producción ideológica de la oligarquía. La capacidad de penetración de la ideología burguesa aseguraba su efectividad por el sustento que le otor-

\footnotetext{
5 La idea de Marx y Engels por establecer un nuevo Estado sobre las ruinas del Estado burgués, para los anarquistas significaba imponer una nueva clase, la de los proletarios, que al institucionalizarse como partido político, entraría al juego de la distorsión de la realidad, del ideologismo (Ver Lehning, Arthur, 2004: 78 y ss).
} 
gaba el cúmulo de principios normativos y de insumos de conciencia que terminaban por coartar los restos de libertad y ahogar los empeños por crear sus propios comportamientos y sus propias visiones. Como lo sostiene el filósofo argelino post estructuralista Louis Althusser (1970), la ideología no dice qué son las cosas, sino cómo posicionarse frente a ellas, para lo cual se vale de sus rituales y sus prácticas. En otros términos, el sujeto o grupo social da cuenta de su situación de existencia, replicando los términos con los que la ideología le ha imputado su condición. Ello se explica porque las ideas de las fuerzas políticas gravitantes tienden a imponerse al resto de la sociedad, no sólo por medio de la violencia física, sino también por algo más subliminal: la violencia simbólica. En virtud de ella, los medios de difusión disponibles, el marco institucional vigente y la propia ideología despliegan su superioridad intelectual, ejerciendo un control sobre los medios de producción mental del resto de la población e imponiéndole sus ideas rectoras. Dice Marx al respecto: "Las ideas de la clase gobernante son en cada época las ideas rectoras, es decir, la clase, que es la fuerza material gobernante de la sociedad, es al mismo tiempo su fuerza intelectual, su fuerza rectora» (Marx y Engels, 1969: 64). De allí que, producto del proceso de deformación de la realidad que moviliza la ideología, un individuo cualquiera puede manifestar su condición y realizar su función, sin que tenga conciencia de ello (Ricoeur, 2006: 128).

Esta condición heteronómica de la ideología tiene un efecto directo sobre el sujeto desde el momento que su existencia aparece determinada por un sistema de creencias impuesto por la cultura dominante que lo determina en sus actos, en la conformación de sus ideas y en los papeles que se le asignan en el marco de sus relaciones de producción. El resultado concreto es que este sujeto acepta sin cuestionarse su sujeción, cancelando cualquiera posición que se aparte de lo que los otros le dictan. Desde el punto de vista de la crítica de la ideología, el pensamiento hegemónico de la clase gobernante es visto como la réplica del «estado religioso», cuya característica central es su proyección a una esfera con significación autónoma, separada de la vida real. Se crea el ente institucional fundado en el poder legitimatorio de las interpretaciones míticas, religiosas o metafísicas de la realidad, tanto del cosmos como de la sociedad (Habermas, 1986: 73). Se cita en el ensayo de Jorge Larraín la opinión de Nicolo Maquiavelo, el primer pensador de la burguesía temprana, que describió el fenómeno social de la dominación religiosa como una patología alienante, quien afirma en El Príncipe de 1513:

Nuestra religión ha glorificado nuestros hombres modestos y contemplativos por sobre los hombres de acción. Ha asignado como el más alto bien del hombre la humildad, abnegación y el desprecio por las cosas humanas [...]. Este patrón de vida, por lo tanto, pareciera haber hecho débil el mundo, y habérselo entregado como una presa a los malvados quienes lo dirigen exitosa y seguramente, ya que son bien conscientes de que la generalidad de los hombres, con el paraíso por su fin, consideran la mejor forma de soportar, en vez de vengar sus heridas (Larraín, 2007: 10).

Sin que este juicio de Maquiavelo responda aún a la teoría general de las ideologías, lo que ocurrirá varios siglos más tarde, su sentido y alcance remite a las condiciones de enunciación del discurso filosófico de la modernidad que reveló un rechazo frontal contra la supremacía religiosa medieval como poder tutelar. Con la construcción de este escenario secular, con la imagen desvalorizadora y crítica del poder de la iglesia, el mundo se preparaba, teóricamente al menos, para abrir los espacios históricos necesarios al advenimiento del proyecto de la modernidad. Con razón, tiempo después Carlos Marx atri- 
buirá el origen de la crítica al paradigma teocéntrico y a las corrientes del conocimiento escolástico del período premoderno.

La materia que ocupó el centro de las reflexiones de pensadores y filósofos bajo el dintel de una nueva época fue el tema de la política y sus diferentes formas de dominación. Aunque los planteamientos de la burguesía industrial estuvieron dirigidos a criticar y denunciar los signos de hegemonía que reflejaba la práctica única del poder religioso al interior de la sociedad regida bajo el orden servil, no se puede soslayar, sin embargo, que el propio discurso anticlerical burgués contenía en su crítica sus particulares afanes de supremacía social y política. Marx fue el primero que vio, tras la palabra emancipadora, justiciera e igualitaria de la burguesía, el ocultamiento de las contradicciones históricas de la sociedad a causa del modelo capitalista de desarrollo, cuya fuerza acrecía al promediar la última parte del siglo XVIII. La tendencia a construir un discurso que disfrazara las verdaderas intenciones de poder de un grupo o de una élite era, por definición, el sesgo de la ideología, y el recurso al que se apelaba para tensionar los términos de ese discurso era el sistema de preferencias simbólico del lenguaje que figurada o imaginariamente replicaba las condiciones de existencia de la sociedad, legitimada por la clase dirigente. Con este expediente, se morigeraba o, en forma abierta, se ocultaba el antagonismo o la conflictividad que encerraba todo modo de producción capitalista. Como lo explica Althusser:

Si bien aceptamos que la representación de las condiciones reales de existencia de los individuos está determinada en última instancia por las relaciones de producción y las relaciones derivadas de ella, diremos lo siguiente: toda ideología, en su formación necesariamente imaginaria, no representa las relaciones de producción existente (y las otras relaciones que de allí se derivan) sino ante todo la relación (imaginaria) de los individuos con las relaciones de producción y las relaciones que de ellas resultan. En la ideología no está representado entonces el sistema de relaciones reales que gobiernan la existencia de los individuos, sino la relación imaginaria de esos individuos con las relaciones reales en que viven (1970: 17).

La marca de la explotación que hay en torno a las relaciones de producción en la sociedad industrial es representada por la ideología de manera equívoca mediante un discurso falso que encomia la imagen de la unidad y la cohesión sociales. El factor que mejor se presta para afirmar esta imagen distorsionada de la realidad es lo que Jorge Larraín define como "mercado", es decir, el intercambio capitalista de mercaderías. Siguiendo a Marx, describe esta interacción como una actividad igualitaria, puesto que los valores que se intercambian son equivalentes. En este intercambio uno y otro se sienten propietarios, por lo que la ocupación o función que deriva de la división proverbial del trabajo queda en este caso anulada. Concluye indicando que «el mercado funciona por la realización de la igualdad, la libertad, la propiedad y el auto-interés» (Larraín, 2007: 86). Sin embargo, el trasfondo de este proceso de construcción de la imagen unitaria muestra algo muy distinto, ya que el discurso capitalista calla, más allá de esta ilusoria igualdad y libertad, la verdadera fisonomía del proceso de intercambio de mercaderías. Nada se dice, por ejemplo, de la apropiación que el capitalista hace de la plusvalía producida por el trabajador, escamoteando lo que legítimamente le corresponde como "hacedor» directo del objeto. «Pero la realidad detrás de esta apariencia es que los trabajadores están obligados a vender su fuerza de trabajo si quieren sobrevivir, precisamente porque han sido privados de sus medios de producción» (Larraín, 2007: 88). 
También en la reproducción de las relaciones de producción se oculta el antagonismo de clase que se genera como consecuencia de la división técnico-social del trabajo. En concreto, según Althusser, lo que se replica es la reproducción de la fuerza de trabajo en términos de salarios, valor con el que se compra la fuerza de trabajo de un obrero, y que compromete al asalariado a mantener el pacto laboral con el capital, representado por el propietario, quien le «concede» un reconocimiento a sus demandas. En ello va la satisfacción de sus necesidades básicas de alimentación, de vestuario, de salud, de educación y, por el otro lado, el propietario se asegura que el trabajador estará dispuesto a presentarse a la mañana siguiente, y todas las santas mañanas, a la entrada de la empresa.

\section{LOS APARATOS IDEOLÓGICOS DE ESTADO Y LA COACCIÓN SIMBÓLICA}

Nada de estas distorsiones sería posible si la cultura dominante no contara con una batería de dispositivos con la sola misión de preservar la hegemonía de los sectores privilegiados de la sociedad mediante lo que se podría llamar «la dictadura del propietariado", ejercida por quienes detentan el poder bajo la égida del Estado. Los órganos de Estado que se ordenan en función de un gobierno nacional, están concebidos justamente para robustecer y prolongar su supremacía sobre el total de la sociedad. La posesión y conservación del poder se hace a través de mecanismos de presión y de represión que se encargan de mantener vivos los principios, valores, normas y visiones que al ente estatal le interesa cautelar. Esta práctica se convierte en una política definida en cuanto la hegemonía del poder no reconoce otro contenido que el que promueve su discurso, cancelando cualquier asomo de diversidad de grupos o segmentos sociales no adscritos al círculo de los favorecidos del sistema. Para ello cuenta con sus propios aparatos de dominación y de persuasión que reafirman la autoridad e imponen sus códigos culturales, favorables a los intereses de grupos o alianzas de grupos. Como lo sostiene Althusser, «ninguna clase puede tener en sus manos el poder de Estado en forma duradera sin ejercer al mismo tiempo su hegemonía sobre y en los aparatos ideológicos de Estado» (1970).

Para este pensador, los aparatos del Estado se describen de acuerdo a las funciones que les corresponde cumplir en el seno de la sociedad. Por una parte, están los aparatos represivos de Estado y, por el otro, «los aparatos ideológicos de Estado». Los primeros se caracterizan por ejercer la represión, mediante el uso de la violencia física, «por lo menos en situaciones límites». Sus agentes son parte del gobierno, de la administración, del ejército, de la policía, de los tribunales, de las prisiones, de los manicomios. En tanto, los «aparatos ideológicos de Estado» son entidades encargadas de construir un sistema de creencias que explique las bondades del régimen gobernante. Son agentes externos de la ideología y distorsionadores del conocimiento de la realidad (Larraín, 2007: 27). Pertenecen a una variedad de instituciones privadas llamadas a difundir aquellas definiciones, valores y rituales ideológicos que mantengan vivo el principio de cohesión social, su reproducción y su irradiación, de acuerdo con los parámetros culturales prevalecientes. Son parte de este aparataje institucional: la escuela, las iglesias, los partidos políticos, los sindicatos, la prensa, la literatura, el teatro, la pintura, la escultura, en una palabra, todo aquello capaz de expresar la visión de mundo dominante. ${ }^{6}$ Si bien los aparatos ideológi-

6 En su trabajo Althusser reconoce ocho formas de control institucional: los aparatos ideológicos de Estado 
cos funcionan por medio de la persuasión, no se puede descartar, sin embargo, un tipo particular de violencia que, a diferencia de los aparatos represivos que recurren en determinados momentos a la coacción física, resulta más bien una clase de violencia simbólica que apunta a reprimir los bienes culturales como ocurre con la censura, con los códigos, con las recusaciones, las desvalorizaciones o las discriminaciones.

El uso de la violencia explícita de los aparatos represivos de Estado tiene un cometido que, partiendo de sus supuestos ideológicos, se traduce en aplicar la fuerza para frenar cualquiera interpretación que ponga de manifiesto la naturaleza expoliadora de las relaciones de producción. Auxiliares de esta acción represiva son los aparatos ideológicos de Estado, medios de producción intelectual subordinados a los objetivos de los grupos minoritarios. Al irradiarse al campo del proletariado, las ideas privilegiadas por el poder terminan por legitimar las condiciones capitalistas de trabajo, desbaratando todo intento por generar ideas alternativas que sopesen la realidad desde una perspectiva proletaria. La ausencia de mecanismos de producción subalternos obliga a los segmentos asalariados de la sociedad a someterse a las formas ideológicas impuestas. "Las ideas producidas por la clase dominada, al no controlar los medios de producción intelectual, tienden a reproducir ideas que responden a los intereses de la clase dominante» (Larraín, 2007: 68). Es esta supremacía ideológica la que configura un cuadro de violencia simbólica que marcará la trayectoria de las luchas populares en torno al eje dominación versus resistencia, o si se quiere, ideología versus emancipación. Es una coacción simbólica que se ejerce sobre los dominados para asumir obligadamente un sistema de representaciones sobre el mundo, la naturaleza y el orden social.

\section{LAS IDEAS LIBERTARIAS EN EL CONTEXTO DE LA DOMINACIÓN IDEOLÓGICA}

El desarrollo del anarquismo en medio de las sociedades, como las latinoamericanas, dominadas por la supremacía ideológica de grupos elíticos, se lo ha representado como un campo de Agramante donde el anarquismo ha librado grandes batallas por neutralizar la hegemonía cultural administrada por los sectores capitalistas burgueses. La red de antagonismos está urdida entre quienes detentan el poder y, por lo mismo, acceden de manera ilimitada a los medios de producción y quienes, por el contrario, carecen de las herramientas para generar sus propios productos mentales. La posición especulativa que acompaña las posiciones elitistas constituye la principal arma para desbaratar los intentos hegemónicos del bando contrario. Este movimiento totalizador es denunciado por la corriente ácrata, basándose en que la ideología distorsiona los términos reales en que se sustenta el modelo de desarrollo burgués con el fin de ocultar las verdaderas contradicciones que se dan en los procesos de producción capitalista, como el lugar que le corresponde al proletario, de acuerdo con su posición dentro de las relaciones de producción. La clase proletaria aparece subordinada a la clase propietaria que es la poseedora del capital. Kropotkin con su lema «a cada uno según su capacidad y a cada cual según su necesidad» puso en evidencia las asimetrías sociales generadas por el sistema de ex-

asociados a la religión, a la educación, a la familia, a lo jurídico, a lo político, a lo sindical, a la información y a la cultura. 
plotación capitalista, y que el discurso ideológico se encargaba de disimular por medio del expediente del acomodo de las relaciones de producción al sistema. La respuesta al encubrimiento institucional por parte del anarquismo fue la de explicitar en sus textos la cadena de abuso, exclusiones, contradicciones y contubernios que genera el ejercicio de una potestad que se incuba dentro de los territorios del poder.

La acción libertaria se realiza a través de la difusión de su ideario, siguiendo el sello doctrinario de la tradición iluminista que ve, desde el punto de vista simbólico, al hombre como una cantera de perfectibilidad infinita, y no como un sujeto sometido a una estructura ideológica autoritaria. Liberado el anarquismo de toda acción conculcadora, desecha de sus prácticas códigos que apunten hacia la inversión de la imagen de realidad. Ubicar al anarquismo dentro de la textura ideológica de los movimientos socialistas de mediados del siglo XIX, supone incluir a la acracia en las luchas históricas por la conquista del poder, lo cual no es congruente con los conceptos y definiciones contrarios a la autoridad que ha caracterizado el posicionamiento del anarquismo en el período de la modernidad. Por esto mismo, es opinable la lectura que, en 1985, hace Ángel Cappelletti de esta vertiente socialista. La condición ideológica con la que este autor argentino califica la doctrina libertaria contradice la inspiración emancipadora del movimiento que busca crear un nuevo orden a partir de sus condiciones de existencia, de trabajo, de salario. La ideología, con su carga totalizante, se contrapone a una conciencia libertaria que rechaza el control de significados que define el mundo como una entidad ya formada. El anarquismo se representa la realidad en la medida que construye la idea de mundo a partir de la base concreta de la existencia, afirmando una mirada que enfrente la realidad histórica y asuma las necesidades reales de los sometidos por un sistema que replica la figura hegeliana de amo y siervo que el anarquismo quiere superar. Esta confianza en la capacidad humana para forjarse un horizonte nuevo, más allá de las restricciones de una cultura paternalista y absorbente que legitima el discurso ideológico, es lo que marca la diferencia entre este movimiento doctrinario y el resto de las corrientes ideológicas, incluyendo aquéllas del mundo progresista.

Cuando Paul Brousse habló de la Idea, en 1877, para referirse al anarquismo, aludía a aquella fuerza viva libertaria que daba cuenta del proyecto social emancipador, cuyas raíces se fijaban en un ámbito de realidad material donde la condición de los individuos estaba determinada por los hombres que viven, que trabajan, que luchan por un salario justo, que producen material y mentalmente. Como Idea es una denominación sustentable, desde la óptica libertaria, pues es la resultante de la concepción materialista de lo real donde caben los individuos reales, su actividad y las condiciones materiales en que viven (Ricoeur, 2006: 113). La Idea no está concebida como un movimiento cuya operatoria está destinada a consumarse en un no lugar y en un no tiempo, sino que se manifiesta como una apertura hacia un mundo nuevo, distinto al orden represivo vigente. «La Idea avanzará [señala Brousse] no sobre el papel, no sobre un periódico, no sobre el cuadro; no será esculpida en mármol, ni tallada en piedra, ni colada en bronce: marchará en carne y hueso, viva, ante el pueblo» (Colson, 2003: 125). Cuando ésta deja de ser carne y hueso, se aleja y se divorcia de la vida real, entra al campo del idealismo, o sea, al campo de la ideología (Ricoeur, 2006: 113). En consecuencia, la Idea no es patrimonio ni de un grupo, ni de una clase, ni de una alianza, sino que corresponde a lo que en su momento fueron «las ideas líderes y progresistas generadas en la Revolución Francesa», imágenes rectoras que representaron el avance de burgueses y proletarios por sobre el régimen feudal (Larraín, 2007: 77). Según Larraín, no fueron estas representaciones mentales líderes, ideológicas; sin embargo, tan pronto éstas se pusieron al servicio de los 
grupos de poder, distorsionando las nuevas relaciones de producción y oponiéndose a la realidad, devinieron ideológicas.

\section{LA DRAMATURGIA ANARQUISTA COMO EXPRESIÓN ESTÉTICA DE LA DESIDEOLOGIZACIÓN}

Dentro de la multiplicidad de vías que el anarquismo utiliza para contrarrestar la interferencia ideológica del discurso dramático tradicional, la escritura dramática aparece como una de las contraversiones de mayor relevancia en el campo de la producción libertaria de bienes culturales. Ésta, junto a la práctica teatral, contribuía a abrir nuevos horizontes de comprensión que les permitiera tener conciencia cabal de las condiciones materiales reales en que vivían los sectores excluidos del sistema y, por lo mismo, ignorados como contenido artístico de la literatura de la época. Su inclusión como sustancia dramática corregía una omisión voluntaria que se explicaba por razones de aseguramiento de la estabilidad institucional de la República. La sola mención a los escenarios en los que circulaban estos grupos marginales, haciendo públicos sus proyectos y expectativas, significaba introducir factores disociadores que resentían las representaciones de paz, progreso e inclusividad que el discurso oficial difundía a través de sus aparatos de comunicación, entre los cuales la literatura realista de inspiración burguesa cumplía una destacada labor. La génesis del discurso dramático libertario se inscribe, por lo tanto, dentro de las estrategias culturales del movimiento anarquista por alentar el surgimiento de una conciencia emancipadora de la diáspora social y cultural, a partir de las certezas que ofrecía la representación de un mundo de necesidades y los esfuerzos de sus exponentes humanos por producir los recursos que satisficieran dichas necesidades. Para ello, no bastaba con apropiarse de los procedimientos empleados por el arte heredado que no hacían otra cosa que replicar las imágenes propuestas, de acuerdo con las reglas impuestas por lo que Proudhon denominaba los mayorazgos literarios. Había que crear un arte nuevo que evolucionara libremente, «sin ninguna regla que lo limite en adelante» (Reszler, 2006: 8).

Este programa dramático reaccionaba ante el rumbo equívoco del proceso de ideologización de las fuentes de producción de los discursos romántico-realistas que convertían la propuesta de mundo en un símbolo del principio de autoridad. La respuesta de la obra dramática anarquista se tradujo en la asunción de una clase de arte cuya función central fuera la de revelar aquellos niveles de realidad que el discurso artístico ideológico silenciaba o reprimía en nombre de un patrón de belleza aristocratizante de naturaleza eurocentrista. Los signos, imágenes y representaciones de la textualidad dramática, referidos al universo material de los hombres reales, a su actividad y a las circunstancias efectivas donde sobrellevaban sus existencias, se dirigían principalmente a recuperar los espacios que constituían el lugar donde estos sujetos concretos habían emprendido sus acciones y realizado sus liturgias. Esta práctica ayudaba, asimismo, a cambiar el concepto de vida material y el papel que les correspondía en la sociedad, según la potestad de los códigos culturales vigentes. Todo ello iba a ser posible en la medida que el texto diera lugar a la reafirmación de las actividades de cada individuo o grupo para enfrentar y resolver sus necesidades básicas, de las cuales la producción de los mecanismos para satisfacerlas sería el eje dramático de las historias de vida representadas. La mirada del dramaturgo se detenía en aquellas zonas que revelaban los escenarios objetivos dentro de los que los 
sujetos, igualmente reales, construían un modelo de existencia material, y dentro de «la perspectiva de una filosofía antiideológica, antipolítica» (Reszler, 2006: 20). El texto se hacía cargo del hecho de que dentro de esta dinámica no sólo creaban sus mecanismos de supervivencia, sino que, además, producían su vida concreta (Ricoeur, 2006: 55). Este programa dramático libertario salía al paso de las versiones prejuiciadas que ofrecía de este mismo espacio social la dramaturgia oficial, restándole valor a las demandas o caricaturizando sus figuras, sus relaciones y sus modos de ser. Para los ácratas, la literatura se concebía como el mecanismo verbal por definición destinado a formar conciencia de las condiciones y circunstancias en las que el individuo debía enfrentar los antagonismos sociales de una sociedad que sufría los efectos desmembradores de una política de relaciones económicas jerarquizadas de producción. La pieza anarquista se sumerge en la materia profunda del modelo capitalista para poner de manifiesto el choque entre el capital y el trabajo, causa principal de la degradación y enajenación que sufre el hombre trabajador, y que el arte dominador oculta por razones de sustentación del gobierno de las minorías. Este contradiscurso literario se basaba en una reescritura de la realidad que incursionaba en aquello material y espiritual que daba unidad y sentido a un mundo otro que permanecía ausente al conocimiento, inclusive de los propios actores de la marginalidad.

Pensar una dramaturgia que efectivamente se pusiera a cubierto de las distorsiones del sistema representacional de la ideología suponía quebrantar los cánones regulares de la creación dramática y desafiar la institucionalidad estética dominante. Ingresar al repertorio de preferencias literarias de la época temáticas vinculadas a las contradicciones sociales y económicas generadas por los procesos de producción capitalista, con un gran impacto, por lo demás, en el campo de la moral ciudadana, implicaba la confrontación directa con los tópicos de la institucionalidad realista, afín a los intereses del poder burgués en funciones. Del mismo modo, introducir en la composición dramática libertaria planos de construcción innovadores, como la perspectiva endógena o los finales abiertos de las piezas dramáticas, prefiguraban una situación de ruptura que se materializaría en Chile sólo mucho después en el conjunto de expresiones dramáticas adscritas a las preceptivas poéticas vanguardistas. Esta novedad formal se explica, no tanto como réplica del espíritu de experimentación que se venía manifestando en la producción artística europea de fines del siglo XIX, pero sí por la vocación libertaria que inspiraba a los creadores ácratas, la que se traducía precisamente en la objeción de hecho a toda normatividad o regulación artística que interfiriera el libre ejercicio de la espontaneidad creativa. «El sometimiento a los criterios de gusto propios de una época y la asunción del conjunto de reglas de un momento específico de la historia del arte son prescripciones reñidas con la definición que el espíritu libertario reconoce en sus poetas [...]» (Pereira Poza, 2005: 115). Para Bakunin, esta subordinación estética hacía que los artistas se convirtieran en «auxiliares naturales del sacerdocio y del despotismo contra la libertad de los pueblos [...] ellos enseñaron a las masas a soportar su indignidad y su indigencia por la contemplación de sus maravillas» (Reszler 2006: 47).

Asumido el papel de discurso dramático desideologizado, el dramaturgo anarquista produjo un tipo especial de obra que garantizara su práctica representacional al margen de cualquier compromiso ideológico. Para llegar a esta condición, reconoció en la constitución de la forma y de la materia dramáticas las contenciones necesarias para mantener el sentido y el alcance del texto alejados de la impronta encubridora de la ideología. Si se hace una revisión exploratoria de los textos anarquistas conocidos a comienzos del siglo XX en Chile (Pereira Poza, 2005: 197-358), la constante que atraviesa cada una de 
estas composiciones es la de articular forma y contenido con miras a plasmar una determinada visión de mundo que responda a la especificidad y validez real del espacio social que se busca representar, oponiendo, en los términos de Marx, la realidad a la ideología. El mecanismo literario que interviene en este cometido artístico consiste en incorporar como material dramático «la vida humana real», es decir, aquélla que da cuenta de los individuos que hacen de su jornada diaria una lucha por ganarse el sustento, por mejorar sus condiciones de existencia, por estrechar sus relaciones con los demás, por plasmar la simplicidad de sus costumbres. La apertura a este universo diaspórico sigue la línea de la contracultura de resistencia que ve en el texto producido la oportunidad de revelar el proceso real de vida por medio de lo que Marx denomina un «lenguaje de la vida real» (en Ricoeur, 2006: 14), que muestra las cosas tal como son y al margen de la distorsión que de ellas hace la representación ideológica, según los intereses en juego de determinados grupos de poder.

\section{INNOVACIONES FORMALES PARA LA DEIDEOLOGIZACIÓN DEL DISCURSO DRAMÁTICO}

Formalmente, la producción dramática libertaria presenta, entre otras, tres características que concurren a la concreción del discurso desideologizado: la perspectiva endógena del dramaturgo, la apelación al destinatario y el final abierto. Cada uno de estos aspectos tiene una función complementaria en la construcción de la obra que apunta a reafirmar la condición histórica del discurso libertario.

Con la perspectiva endógena, el dramaturgo escoge como punto de habla el espacio proletario profundo, conformado por los individuos que hacen de su vida un continuo bregar por la subsistencia, dada las condiciones adversas que ofrece el sistema capitalista para alcanzar grados de satisfacción de las necesidades básicas. Este compromiso con la marginalidad social obedece al imperativo de utilizar un registro lingüístico que se mimetice con la vida concreta por lo que «el lenguaje de la vida real» es enunciado "desde» las fuentes mismas de la realidad marginal. A lo que se quiere llegar es a ese gran arte, fruto del genio inventivo de la colectividad y en el cual el escritor no es más que el intérprete de esos impulsos colectivos. Esta particularidad creativa tiene para Proudhon el sentido de un arte sincrético en el cual el arte no sólo es «el arte del pueblo y para el pueblo, sino también por el pueblo»(Reszler, 2006: 8). Con ello, se elimina cualquier asomo de idealización burguesa, antesala de la imagen falseada de la realidad del discurso ideológico. Igualmente, esta mirada íntima de la diáspora social, de la que forma parte el autor, marcará la diferencia con la visión distanciada y aséptica del realismo burgués que habla «sobre» la vida del pueblo.

De la citada antología, que reúne siete textos dramáticos libertarios chilenos divulgados entre los años 1895 y 1927, la totalidad de ellos representan historias que están dramatizadas desde las capas sedimentales del mundo histórico local. La dedicatoria con la que introduce ;Grilletes! (1927) el seudonominado Alfred Aarón, deja testimonio de que su obra, más que una ficción, es una obra social destinada a dar a conocer en parte siquiera aquellos mártires del Ideal Anarquista. El dar a conocer corresponde a una toma de conciencia que busca la escritura libertaria, a partir de la exposición, y no de la recreación de los hechos vividos y experimentados por hombres vivos que comparten el mundo del hablante, tarea del artista que ya había sido visualizada por Kropotkin, quien, 
a propósito del compromiso con el «arte en situación», apela al creador: «[...] tú no puedes permanecer neutral; vendrás y tomarás el partido de los oprimidos, porque sabes que lo bello y lo sublime —como tú mismo- está del lado de aquéllos que luchan por la luz, por la humanidad, por la justicia» (1985: 65).

La apelación al lector, como otro de los rasgos formales de la dramaturgia anarquista en Chile, constituye otra de las estrategias discursivas que busca restablecer los términos de la verdadera realidad social, subyacente al sistema capitalista de desarrollo. La intención estética de rescatar de la mirada distorsionadora, aquellos niveles de realidad que remiten al mundo social objetivo, considera la figura del lector, ente crítico central para restituir lo vivencialmente escamoteado por la escritura convencional, como uno de los factores de articulación de la cadena de formación de sentido de la dramaturgia anarquista. Esta conexión con el lector virtual es el cable a tierra que previene al dramaturgo de cualquier conato de imaginería que produzca una representación artificial de la realidad, a la usanza de los códigos romántico-naturalistas. Por el contrario, la apelación al lector es el recurso que consigue integrar al destinatario en el proceso colectivo de construcción de sentido, separándolo de la condición de autómata que el arte dominador ha hecho de él mediante la repetición de palabras, fórmulas, ideas y visiones que provienen de los otros, de aquéllos que buscan imponer modos de pensar y de hacer, coartando el libre ejercicio de la razón. Esta interacción autor-destinatario, mediada por la figura del lector virtual, alcanza particular relevancia en el discurso dramático anarquista, debido a que la pieza busca concretar una imagen potencial del mundo de forma que las posibilidades de plasmación descansen en el lector individual, de acuerdo con sus propias ideas, creencias y valores. Esta coproducción salvaguarda las intenciones de imponer una determinada visión, desde el momento que el nuevo orden perseguido será el resultado de la lectura personal del destinatario de las señales y contenidos residuales proporcionados por el texto mismo. En virtud de este ejercicio de autonomía mental, el discurso ácrata incentiva a sujetos libres, críticos y dispuestos a incorporarse al plan de revisión crítica de las bases del orden burgués y a contribuir a la edificación de uno nuevo, más justo, soberano y solidario. "Esto es posible por el efecto desencadenante que produce el conjunto de sugestiones que trae el drama en su realización y los numerosos vacíos informacionales que lo atraviesan", se lee en el estudio preliminar que acompaña a Antología crítica de la dramaturgia anarquista en Chile (Pereira Poza, 2005: 129). Los variados lugares de indeterminación desencadenan la actividad del lector, dejando atrás la condición pasiva del receptor subalterno tradicional.

Complementario del recurso formal anterior es el que se refiere a la técnica de los finales abiertos que permite dejar en suspenso el término de la acción dramática. Es el propio texto el que guía al lector hacia territorios ilimitados donde puede instaurar soberanamente su propio universo libertario, en una actividad alejada de toda imposición o prejuicio. Tal es así, que el mundo creado no es el que la obra prefigura, sino el que resulta de las vivencias, intereses, deseos, expectativas y saberes acumulados en su experiencia de vida y bajo condiciones de existencia particulares. Esta actividad productiva va por un camino convergente con la praxis libertaria que reconoce el derecho de cada individuo a construir su propio espacio, conforme sus potencialidades emancipadoras (Colson, 2003: 260). El diseño con el cual se presenta el mundo ante el lector considera la presencia de incitaciones emancipadoras que vuelven casi imposible su neutralidad, induciéndolo a ser parte de un movimiento de liberación respecto del entorno asfixiante que ahoga cualquier intento del sujeto para forjarse su propia estampa de la realidad. Se espera que detrás de este acto de independencia que tiene lugar dentro del proceso de decodificación 
a que lo convoca el texto con final abierto, su espíritu de lucha, adormecido por siglos de dominación mental, despierte a la acción y se sume a los agentes libertarios para provocar los cambios que la sociedad reclama.

Desde el punto de vista de la recepción y de la organización de los desenlaces del discurso dramático libertario, la indeterminación del curso final de las acciones emprendidas por las figuras dramáticas anarquistas se presenta como el problema principal que debe resolver el lector en términos de interpretar el destino final de las situaciones expuestas. La lectura esperada supone una proyección coincidente con los principios, definiciones y metas que el anarquismo postula en la tarea por encontrar un cambio real de las condiciones de existencia que han prevalecido bajo la lógica bipolar de un sistema que se funda en las jerarquías. Rompiendo con las formas tradicionales del drama realista, los textos ácratas chilenos muestran la novedad de que ninguno de ellos resuelve los conflictos dramáticos desarrollados a lo largo del relato; por el contrario, se suspende la respuesta al problema planteado, a la espera de que el lector real le impute el sentido que, a su entender, mejor calce con la vocación de cambio que promueve el pensamiento libertario. En esta línea, es sugestivo el remate que el dramaturgo da al enfrentamiento de fuerzas en Flores rojas (1912) de Nicolás Aguirre Bretón. A punto de concretarse el matrimonio por conveniencia de la hija del patrón, irrumpe en la ceremonia el joven jardinero de la heredad, reclamando el derecho de amar a la muchacha, luego de una larga relación truncada por intervención del padre. Decide llevársela, no obstante las prevenciones del sacerdote que les advierte sobre la imposibilidad de ese amor, ya que son hermanos por línea paterna. Los enamorados, a pesar del estigma social con que se les quiere condenar, optan por perseverar en su proyecto de vida:

PADRE CRUZ: No, Teresina, no puedes ser de Juan porque es tu hermano.

TERESINA: Así le quiero, mi hermano, mi compañero inseparable conforme se lo juré (Pereira Poza, 2005: 292) .

\section{CLAVES DESIDEOLOGIZADORAS DEL CONTENIDO DE MUNDO DEL TEXTO DRAMÁTICO ANARQUISTA}

En contraste con la dramaturgia anterior, el texto libertario asume su tarea de construcción de la imagen de mundo, escogiendo un modo directo de representación que busca, como lo afirma Kropotkin, penetrar en la choza del campesino. Este enfoque social se ocupa del universo del obrero de la ciudad y del campo, mostrando de él lo que constituye el entorno, pero exponiendo también en el acto de la escritura lo que son las necesidades del hombre concreto y actual, las condiciones materiales en que vive y trabaja, la inspiración moral como eje del repertorio humano de conductas y comportamientos y sus esfuerzos por mantener y enriquecer sus espacios culturales que lo definen como sujeto y lo llevan a compartir sus ideas, creencias, costumbres, valores, proyectos de vida y visiones de mundo. No es que su opción representacional replique, en algún grado, el realismo literario que predomina en las prácticas escriturales de la época, y que lo define como un arte reafirmador del principio de autoridad. Por el contrario, la manera de acercarse al hombre y su circunstancia vital sigue la línea representativa de lo que Proudhon llamaba «el arte en situación», es decir, un arte que recrea el espacio y el momento en el que se despliegan estas existencias marginales. Esta espontaneidad inventiva es el gesto 
a partir del cual esta nueva estética se distanciará definitivamente del arte dominador, caracterizado por seguir los dictados del conjunto de reglas inmutables impuesto por los criterios de belleza artística tradicionales y por privilegiar el marco determinista del realismo canónico que explica la realidad desde el principio positivista de la causalidad telúrica, genética o histórica. La respuesta va en la dirección libertaria de recoger de la vida de los miles de individuos que vegetan en la miseria y el ostracismo sus aspiraciones, sus logros, sus frustraciones, en fin, todo lo que es parte de la experiencia de vida cotidiana de los sectores segregados de la sociedad. Si la reconstrucción poética del espacio tuviera que llevar un nombre en este tipo de obras, por cierto que no sería el del realismo burgués, ese «superficial ideal de la burguesía del siglo XIX» (Read, 1976: 15), sino el del realismo socialista libertario que entiende el arte como expresión de la vida en su más descarnada expresión, representando la vida del hombre marginal en su más genuina realidad, subrayando su dolorosa existencia, pero, también, su potencial espiritual en virtud del cual podrá alcanzar los más elevados niveles de realización personal en pura y soberana libertad.

La constante que se observa en todas las piezas seleccionadas de la producción dramática libertaria chilena apunta a revelar los espacios de la acción en íntima conexión con las coordenadas temporales que remiten a la vida social contemporánea a la enunciación. Sea campo o ciudad, los conflictos se sitúan dentro de los márgenes de un territorio cercano y familiar al lector. La ciudad está focalizada en los extramuros y zonas pobladas de cités, caseríos y rancheríos donde sus moradores conforman un compacto bastión popular; por su parte el campo representa un escenario rural marcado por las carencias y la pobreza material, en donde sus habitantes mantienen aún vivos resabios coloniales. En las piezas con localización citadina - El Sábado (1923), Los Vampiros (1914) y iLos Grilletes! (1927)—, ${ }^{7}$ el interés de la representación no está en la identificación del lugar preciso en que ocurren los episodios dramáticos, sino en la situacionalidad que alcanzan las historias relatadas. Tan es así, que en Los vampiros, por ejemplo, la acotación de entrada ${ }^{8}$ deja establecida la condición universal del espacio y la humanidad de las situaciones expuestas, al reseñar que «La acción se desarrolla en cualquiera de las cinco partes del mundo, pues en todas es común»(338). La alusión nominal del lugar de la acción en las obras restantes refleja la intención del discurso de dar prioridad a la presencia de los personajes en calidad de agonistas de un mundo al cual hay que restituirle el sentido de la vida para hacerlo más habitable. En cuanto a las obras de significación rural - Los Cuervos (1937), Un Hombre (1913), Flores Rojas (1914) y Suprema Lex (1895)_, las alusiones al sector material donde transcurre el acontecer dramático resulta todavía más contenido verbalmente que el grupo anterior. En ninguna de las obras aparece algún elemento identificatorio que refrende su carácter local; más bien se extrema la indeterminación de manera que el lector pueda ejercitar libremente la capacidad de imputar la cartografía que sea más congruente, de acuerdo con la idea que conciba en relación con el nuevo orden. A lo más, se encontrará una genérica referencia «a la campiña chilena»o a «una oficina salitrera» en la acotación de entrada de Los Cuervos y Suprema Lex, respectivamente. Como se puede constatar, la cosmovisión de todas las obras nombradas, en lo que respecta al lugar de la acción, interesa más en lo que tiene de sustento material

\footnotetext{
7 Los títulos corresponden a la selección realizada por el autor en Antología crítica de la dramaturgia anarquista en Chile, páginas 197-358.

8 Sobre los niveles del discurso acotacional, véase mi artículo «La acotación escénica y textual».
} 
para el desarrollo de los conflictos humanos que en la prolijidad descriptiva de los escenarios. Los efectos estéticos quedan a la vista: se cierra toda posibilidad de representar un formato definido de realidad que signifique imponer una determinada mirada o un modo específico de valoración que a la autoridad le importa defender. El entregar todo el dispositivo simbólico al lector para su personal decodificación pone a cubierto al objeto literario de cualquier asomo de intención ideologizante. Revirtiendo esta práctica seductora e invasiva de la escritura burguesa, el código ácrata renunciará a todo aquello que el anarquismo, desde siempre, ha considerado la piedra angular de su filosofía humanista y libertaria: el respeto irrestricto al ejercicio soberano de sus seguidores a crear las bases de la nueva realidad.

La plasmación del arte de la vida real como materia central de sus obras dramáticas encamina la actividad del artista-lector hacia el punto donde brota la facultad creadora del sujeto, en una reafirmación de la capacidad inventiva que, según Proudhon, existe en cada individuo (Reszler, 2006: 24). Desfila por las cuartillas del poeta ácrata la figura del hombre enajenado del mundo moderno que lucha por recuperar el sitial que antropológicamente le corresponde por su condición de sujeto. Se siente desconectado no sólo de los demás, sino también de sí mismo. Es ese sentimiento de enajenación que acompaña a las figuras dramáticas libertarias el que los motiva a revertebrar su naturaleza fragmentada por medio de una fuerza creadora que no sólo las pone en comunión con las esferas simbólicas del mundo representado; además, las impulsa a modificar el sistema económico y social existente (Read, 1976: 16). Estas obras se abren para retratar la trayectoria dolorosa de quienes anhelan encontrar los medios que les permita superar sus necesidades primarias, combatir la depreciación de la fuerza de trabajo y luchar por un salario justo, defender el derecho humano inalienable de vivir en libertad. Se representa en ellas ese universo de trabajadores en cuyo seno se dan las grandes batallas para mantener la independencia ante la embestida capitalista que busca el sometimiento de la clase asalariada. No son ficciones ni reescrituras reguladas por convenciones poéticas heredadas. Son jirones de vida que se esfuerzan por romper el círculo de silencio que el realismo burgués ha dibujado para ocultar las consecuencias demoledoras de un sistema despiadado que condena al trabajador a ser presa de la voracidad capitalista. En Suprema Lex, un dirigente sindical minero encarcelado por presentar un petitorio de mejoramiento económico, o Julián, el modesto inventor de tecnologías, son víctimas de la ambición de un capitalista que le roba su idea en Los Vampiros o Julio, líder campesino condenado a muerte por incitar a la huelga a los trabajadores de un predio en ;Los Grilletes!, son los testimonios vivos con los que el discurso dramático anarquista demuestra cómo los atropellos e injusticias de un modelo económico-social vigente son realidades que, en virtud del escamoteo ideológico del realismo burgués, no trascienden a la población. Corresponden a espacios sociales denigrados, silenciados y, aun, reprimidos por el discurso oficial, lo que el drama ácrata privilegia en virtud de la función reveladora que lo inspira.

También este realismo de vida se ocupa de manifestar artísticamente las ideas, valores y cosmovisión que subyacen al tipo de existencia que sobrellevan en un entorno prefigurado por la cultura dominante.

Las ideas son las representaciones que cada sujeto anarquista se forja a sí mismo en relación con sus propios procesos vitales. Corresponden al universo de bienes culturales que el hombre es capaz de producir, y que apuntan a definir su situación personal y las condiciones materiales dentro de las que le toca vivir. Los contenidos libertarios surgen en respuesta a las simbolizaciones oficiales que se empeñan en fijar una concepción del mundo armoniosa y afirmativa. En los dramas anarquistas, se conforma el sistema de 
ideas afincado en la realidad social misma, separándose de las abstracciones deformadoras que seleccionan del objeto contemplado sólo lo que conviene a las intereses de una cultura elítica. La idea del hombre como ser perfectible, que es parte consustancial del paisaje del nuevo orden que se pretende establecer, está presente, ya sea en los dramas citadinos como campesinos. Por encima de las caracterizaciones básicas, afines a los retratos realistas, el discurso anarquista encomiará los atributos, virtudes y capacidad de lucha que acompañan a la representación del hombre libertario dentro de un contexto de emancipación. Ante los más intensos momentos a los que estos agonistas se ven enfrentados, la decisión de avanzar por encima de los obstáculos será trabajada en los textos como testimonios de una acción que debe servir de ejemplo para quienes se sientan inspirados en la entrega que manifiestan ante las dificultades. Esta concepción del hombre, que no se arredra frente a nada cuando está de por medio el proyecto emancipador, es plasmada en las obras utilizando figuras que encarnan la realidad del sujeto que hace de su vida cotidiana un permanente batallar, atributo que lo guiará para abrazar la noble y justa causa del libertarismo.

Estas figuras, retratadas de acuerdo con el estatuto del tipo humano, simbolizan la grandeza de los héroes anónimos que pueblan la galería de mártires del movimiento, cuya fuerza comunica las energías con las que las nuevas generaciones continuarán la ruta señalada en pos del mejor de los mundos posibles. En consonancia con el sentido emancipador de la escritura, la idea de la libertad enarbolada por los anarquistas no reconoce distingos entre hombres y mujeres en relación con las funciones que les caben en el proceso de instauración de un sistema diferente. Inédita resulta para la dramaturgia de la época el que esta clase de obras delegue en la mujer ácrata el cumplimiento de las más honrosas tareas en beneficio de la permanencia e irradiación de los principios anarquistas. Fiscal de las costumbres y la vida buena de sus compañeros de causa, su actuar servirá para liberar a su marido de las garras del alcoholismo (El Sábado) o hacer justicia por sus propias manos por el encarcelamiento arbitrario de su pareja (iLos Grilletes!) o poner freno a los intentos de prostituirla de quien es el responsable de la prisión de su marido (Suprema Lex). El ejemplo de rectitud y consecuencia que entrega la mujer en las obras libertarias es el mentís a la visión ideologizada que de ella entrega el discurso burgués, atribuyéndole un perfil negativo en términos de desconocer su presencia dentro del proceso de modernización de la sociedad.

Desde el punto de vista de los valores, el proyecto dramático libertario se autoimpone la sustitución de la escala valórica acomodada de acuerdo con los intereses de la cultura privilegiada. Los nuevos valores preconizados por el discurso ácrata apuntan a reafirmar las certezas y percepciones que se tienen de que lo posible constituye el atributo fundamental a partir del cual los postulados suspendidos de la modernidad racionalista del siglo XVIII se pueden repotenciar en esta cruzada libertaria. El grueso de los valores que el anarquismo reactualiza del ideario revolucionario de la Ilustración atraviesa las situaciones y proyectos dramáticos, proporcionando la legitimidad a su pensamiento, cualidad de la que carece la estructura mental de los grupos oligárquicos. Fiel a su contenido humanitarista, el texto investirá a sus figuras dramáticas epónimas de grandes conceptos universales como la libertad, la solidaridad, la filantropía y la fraternidad, contenidos morales que servirán de pauta a la acción de los agentes portadores de la Idea, cuyo fin último es la emancipación de la Humanidad. La invocación de estos preceptos servirá de base al actuar emblemático de los personajes. La obtención del fin deseado se consigue por los dones morales que se poseen más que por la fuerza física desplegada. Para el texto, lo agentes de la acción se transforman en los artífices de la intervención estética de la 
realidad, haciendo del espacio realista tradicional un universo donde las energías morales latentes otorgarán el fundamento del nuevo orden que los anarquistas se proponen crear, contrastando su esencia moral con la intemperancia del mundo capitalista. En cada una de las obras ácratas reseñadas, la fórmula para neutralizar el proceso de inversión llevado adelante por el discurso burgués ideologizado consiste en la resignificación de los valores que han servido de escudo al modelo capitalista. El comienzo está en asignar a estos valores de la sociedad industrial un rostro humano que le dé el sentido de vida auténtica que los tiempos de recuperación de la dignidad individual y colectiva reclaman. El marcado acento ético-moral que acompaña a todas estas obras anarquistas - la suma de reproches, censuras y denuncias que derivan de la presentación del mundo dramático, de la que no escapan los propios trabajadores - es la respuesta al disimulo y al ocultamiento moral que realiza la dramaturgia realista dominante.

Finalmente, la cosmovisión que se plasma en el discurso libertario obedece, de igual manera, a las representaciones de la vida real del anarquismo. La imagen que se propone se proyecta hacia el segmento de la sociedad más afectado por las condiciones impuestas por el gobierno de las élites. La opción depende del hecho de que el drama realista tradicional, por las razones ideológicas ya señaladas en este trabajo, ha ocultado o soslayado todo aquello del mundo proletario que testimonie desajustes, desequilibrios y asimetrías. El texto dramático libertario se caracteriza precisamente porque dice del mundo lo que la cultura privilegiada calla, y lo que se revela alude a las condiciones de vida de los obreros rurales y citadinos, a las segmentaciones sociales nacidas de la fórmula capitalista de la división del trabajo, a los proyectos y expectativas sociales, a las creencias sobre la posibilidad de establecer un orden más justo y solidario entre todos los integrantes de la comunidad. En esta línea, la propuesta libertaria de mundo no deja de plantear algunas interrogantes asociadas principalmente con las posibilidades reales de que este nuevo modelo cultural pueda tener cabida en un espacio donde la ciencia y la tecnología empiezan a ejercer su dominio no sólo sobre la naturaleza, sino también sobre los hombres (Habermas, 1986: 55). Todo esto ha contribuido a que los detractores, y también sus competidores, tilden al anarquismo de utópico y, por lo mismo, irrealizable. Ayuda a esta hipótesis el que el anarquismo en su producción dramática estimule en sus lectores la creación de mundos posibles, en permanente construcción, proyectándose al mejor de los mundos posibles, no obstante lo cual la proposición de mundo libertaria se sitúa por encima del «no ha lugar» que implica etimológicamente la utopía. Este realismo socialista libertario tiene sus instrumentos artísticos de percepción de la realidad muy anclados en la tierra, y el lenguaje real con el que el texto determina los escenarios de la acción tienen su referente histórico y objetivo en la realidad material contingente que le sirve de inspiración. Los asuntos hilvanados en las obras tienen su asiento en espacios concretos, y cuando no - recordemos el caso de Los vampiros - , los personajes reflejan las características personales del obrero-tipo del mundo. Enseguida, el mundo posible anarquista es el eco de comunidades premodernas que practicaron una convivencia en condiciones tales de libertad y solidaridad que la literatura anarquista quiere reescribir en el presente; de ahí su cercanía con todo lo residual que se entreteje en las narrativas populares.

Con estas dos precisiones, las connotaciones negativas adjudicadas al término anarquismo en relación con la utopía quedan superadas, fundamentalmente, porque el discurso dramático libertario no es un discurso fundado en la tergiversación y el ocultamiento, sino, por el contrario, en la recuperación y en la revelación. Los escenarios antagónicos, por ejemplo, que se muestran en la historia de iLos Grilletes!, a causa del conflicto entre el capitalista y el líder campesino por transformar la propiedad privada en propiedad 
comunitaria, replica la lucha secular de los campesinos por trabajar la tierra en condiciones dignas. La insurgencia declarada que tiene lugar en la obra busca restablecer los términos de una experiencia autogestionadora que los campesinos quieren actualizar de versiones anteriores.

La irrupción del pensamiento anarquista en el escenario chileno a fines del siglo XIX significó una auténtica ruptura con los moldes culturales impuestos por la oligarquía reinante desde los albores mismos de la institucionalidad republicana. El derecho que se arrogó el movimiento a significar desde la periferia permitió que los espacios de comunicación social, creados para difundir la palabra y la acción libertarias, afirmaran un concepto de vida alternativo que, por las implicancias que tuvo en el proceso de resignificación de las creencias, valores, costumbres y visiones de mundo, se erigió en un importante foco de resistencia cultural. El carácter confrontacional que alcanzó esta lucha por defender y justificar la autoridad vigente, por un lado, y por denunciar la insustentabilidad de un modelo de desarrollo basado en una falsa conciencia, por el otro, llevó al anarquismo a revelar la voluntad de dominio que subyacía a la propuesta ideológica de la realidad de los sistemas de producción simbólica administrados por el poder. Uno de los canales de divulgación que le correspondió asumir la función de revelar los intentos del discurso oficial de someter a los segmentos de la población más expuestos mediante el engaño y el ocultamiento, fue la dramaturgia ácrata. El punto de vista del texto se ocupó de aproximar el mundo representado a la vida real, testimoniando de manera directa las condiciones de existencia y de trabajo en una sociedad capitalista convulsionada por el antagonismo. La interacción de la obra dramática con los hechos reales contribuyó a construir estéticamente una imagen del mundo, libre de juegos retóricos que disfrazaran la realidad. El programa estético del realismo socialista libertario que el anarquismo implementa para neutralizar las imposturas de la ideología en la literatura, en lenguaje kropotkineano, fue el que hizo posible "penetrar en la choza de cada campesino" con lo cual la dramaturgia libertaria en Chile abrió en la cultura nacional un espacio para representar la realidad local al margen de la escritura ideológica enmascarada de los agentes de la cultura burguesa.

\section{REFERENCIAS}

Adorno, Theodor y Max Horkeimer. (1989). La sociedad. Buenos Aires: Editorial Proteo.

Althusser, Louis. (1970). Ideología y aparatos ideológicos de Estado. Obtenido el 10 de abril de 2008, desde <http://www.cholonautas.edu.pe/modulo/upload/LOUIS\%20 ALTHUSSER.pdf>

Cappelletti, Ángel. (1985). La ideología anarquista. Caracas: Alfadil Ediciones.

Chomski, Noam. (2003). Prólogo. Daniel Guèrin, El anarquismo. Buenos Aires: Anarres.

Colson, Daniel. (2003). Pequeño léxico filosófico del anarquismo. Buenos Aires: Nueva Visión.

Habermas, Jürgen. (1986). Ciencia y técnica como ideología. Madrid: Tecnos.

Kohan, Néstor. (2003). Ideario socialista. Buenos Aires: Longseller.

Kropotkin, Mijail. (1996). La conquista del pan. Barcelona: Ediciones 29.

Larraín, Jorge. (2007). El concepto de ideología. Santiago: Lom. 
Lehning, Arthur. (2004). Marxismo y anarquismo en la Revolución Rusa. Buenos Aires: Anarres.

Marx, Karl. (2008). Cartas. Obtenido el 10 de abril desde el sitio electrónico <www. marxist.org>

Marx, Karl y Friedrich Engels. (1969). La ideología alemana. Barcelona: Ediciones 62.

Mintz, Frank (Ed). (2006). Bakunin. Crítica y acción. Buenos Aires: Anarres.

Pereira Poza, Sergio. (2005). Antología crítica de la dramaturgia anarquista en Chile. Santiago: Editorial de la Universidad de Santiago.

(2002). La acotación escénica y textual. En Siglo XXI. Buenos Aires: VI, 11, primavera, pp. 19-22.

Read, Herbert. (1976). Arte y alienación. Buenos Aires: Editorial Proyección.

Reszler, André. (2006). La estética anarquista. Buenos Aires: Libros de la Araucaria.

Ricoeur, Paul. (2006). Ideología y utopía. Barcelona: Gedisa.

Recepción: mayo de 2008

Aceptación: julio de 2008 